\title{
Pemanfaatan Daun Ungu (Graptophyllum pictum) Sebagai Bahan Dasar Pewarna Alami
}

\author{
Okta Amelia1) , Susi Susyanti2) , Elfa Susanti Thamrinc1), \\ 1) Agroindustril Technology, Institut Teknologi Sumatera, Lampung Selatan, Lampung \\ 2)Design Comunication Visual, Institut Teknologi Sumatera, Lampung Selatan, Lampung \\ E-mail: okta.amelia@itera.ac.id
}

\begin{abstract}
Abstrak
Warna merupakan salah satu daya tarik utama, dan menjadi kriteria penting untuk penerimaan produk seperti tekstil, kosmetik, pangan dan lainnya. pewarna alami telah digunakan di China pada 2600 SM. Hampir semua bagian tumbuhan apabila diekstrak dapat menghasilkan zat warna, seperti: bunga, buah, daun, biji,kulit, batang atau kayu dan akar. Penelitian ini ditujukan untuk mengetahui ketahanan luntur pewarna daun ungu pada tekstil. Penelitian ini dilakukan dengan mengekstrak daun ungu (Graptophyllum pictum) 100 gram dan etanol 96\% 1000 ml dengan lama maserasi 12 jam, 24 jam, 36 jam, dan 48 jam yang kemudian dikeringkan untuk memperpanjang umur simpan dan memudahkan dalam proses pengemasan. Parameter yang diuji dalam penelitian yaitu kadar air pewarna daun ungu, serta laundrymeter. Berdasarkan penelitian yang telah dilakukan kadar air rata-rata yang dihasilkan dari ektraksi sebesar 4,15, nilai laundrymeter 3-4 cukup baik dan crockmeter 4-5 baik.
\end{abstract}

Kata Kunci : Crockmeter, Daun Ungu, Laundrymeter, Pewarna.

\begin{abstract}
Color is one of the main attractions, and the important criteria for product acceptance in many industries such as textile, cosmetics, food and others. Natural dyes have been used in China in 2600 BCE. Almost all parts of plants if extracted san produces dyes, such as: flower, fruit, leaf, seed, bark, stem or wood and roots. This research aims to determine the durability of purple leaf dyes in textiles. The study was conducted by 100 grams extracting purple leaves (Graptophyllum pictum) by using ethanol $96 \% 1000 \mathrm{ml}$ as the solvent with maceration time was various into 12 hours, 24 hours, 36 hours, and 48 hours that were then dried to extend the shelf life and facilitate the packaging process. The parameters tested in the research were purple leaf dye water content, as well as laundrymeter. Based on the research that has been done average moisture content generated from the extraction of 4.15, Laundrymeter value 3-4 is quite good and crockmeter 4-5 is good.
\end{abstract}

Keywords: Crockmeter, Purple Leaf, Laundrymeter, Dyes

\section{Pendahuluan}

Pemanfaatan zat warna alam untuk produknon-pangan menjadi salah satu alternatif pengganti zat warna sintetik. Hal ini dikarenakan pewarna sintetik dapat mencemari lingkungan dan menimbulkan efek karsinogenik pada pemakainya. Kwartiningsih (2009), menyatakan bahwa sejak 1 Agustus 1996 negara - negara maju, seperti Jerman dan Belanda, telah melarang penggunaan zat pewarna berbahan kimia. Larangan ini mengacu pada CBI (Centre for the Promotion of Imports from Developing Countries) Ref.CBI/NB-3032 tertanggal 13 Juni 1996 tentang zat pewarna untuk produk clothing (pakaian), footwear (alas kaki), bedsheet (sprei atau sarung bantal).
Salah satu bahan yang dapat digunakan untuk proses pewarna alami yaitu Daun Ungu (Graptophyllum pictum). Visalakshi and Jawaharlal (2013) menyatakan bahwa pewarna alami dapat diperoleh dari tum-buhan, binatang atau mineral. Hampir semua bagian tumbuhan apabila diekstrak dapat menghasilkan zat warna, seperti: bunga, buah, daun, biji,kulit, batang atau kayu dan akar. Rymbai et al.(2011) menyatakan bahwa terdapat tiga golongan pewarna alami yang paling penting yaitu; tetrapyrrols, tetraterpenoids, dan flavonoids. Sedangkan menurut Malik et al. (2012) golongan pigmen alami yang paling penting yaitu; karotenoids, flavonoid, tetrapirroles dan beberapa xantophylls sebagai astaxanthin. 
Industri tekstil memiliki bahan dan teknik yang banyak digunakan di dunia luas. Industri pewarna merupakan salah satu industri besar. Kesadaran konsumen akan pengaruh warna, industri tekstil dan mode mengeksplorasi aspek ini sangat detail, sehingga menghabiskan sejumlah besar energi dan biaya dalam mengejar warna yang sempurna.

Keberadaan industry pewarna tekstil yang banyak, mengakibatkan kebutuhan pewarna alami semkin meningkat dengan harga yang ekonomis dan tersedia dalam berbagai warna (Scully, 2012). Kasmudjo dan Saktianggi (2011) memanfaatkan daun indigofera sebagai pewarna alami batik denga nilai ketahanan luntur dengan hasil 4-5 yaitu sangat baik. Penelitian ini diharapkan mampu memanfaatkan daun ungu (Graptophyllum Pictum) sebagai pengganti pewarna sintetis pada industry tekstil. Pewarna alami yang digunakan dalam industry tekstil dapat mengurangi cemaran lingkungan dari limbah pewarna sintetis.

\section{Metode Penelitian}

\section{Bahan dan Alat}

Bahan baku yang digunakan untuk pembuatan pewarna alami terdiri atas daun ungu (Grapthophyllum pictum) dan bahan pelarut etanol $96 \%$ dengan perbandingan maserasi 1:10, serta bahan fiksator tawas.

Alat yang digunakan dalam penelitian ini yaitu evaporator, bejana, kertas saring, timbangan, gelas ukur, alat laundrymeter untuk menguji tahan luntur terhadap pencucian serta crockmeter untuk menguji ketahanan luntur terhadap gosokan.

\section{Prosedur Penelitian}

\section{Persiapan Bahan Ektraksi Daun Ungu}

Ektraksi daun ungu dilakukan secara maserasi dengan menggunakan pelarut etanol $96 \%$ dalam variasi waktu $12,24,36$, dan 48 jam. Daun ungu yang terpilih sebelumnya dicuci, dikeringkan, dan dikecilkan ukurannya. Tahap selanjutnya adalah maserasi dengan lama waktu sesuai perlakuan dengan ratio sample dan pelarut 1:10. Setelah proses maserasi, sampel disaring dan dipisahkan bagian padatan dengan larutannya. Setelah didapat cairan kemudian dilakukan pemekatan dengan evaporator. Tahap selanjutnya yaitu fiksasi kain katun dengan menggunakan tawas dan pencelupan kain ke dalam pewarna.

\section{Hasil Dan Pembahasan}

\section{Kadar Abu}

Abu merupakan suatu zat organik sisa pembakaran bahan organik. Analisa Kandungan abu dan komposisinya tergantung pada bahan dan cara pengabuannya (Bahri, 2017). Metode kadar abu yang digunakan dalam analisa yaitu metode AOAC. Berdasarkan hasil penelitian, semakin lama waktu maserasi kadar abu yang dihasilkan semakin meningkat. Nilai kadar abu ini diduga dipengaruhi oleh lamanya waktu maserasi dengan semakin tingginya konsentrasi pewarna.

Kadar abu dilakukan untuk mengetahui jumlah mineral yang ada pada daun Grapthophyllum pictum. Berdasarkan data pada Gambar 1. semakin lama waktu maserasi kadar abu semakin meningkat hal ini dimungkinkan tingkat kemurnian dan dan kebersihan suatu bahan. Hal ini sejalan dengan pernyataan Sandaja dan Atmarita (2009) bahwa penetuan kadar abu berkaitan dengan kandungan mineral yang terdapat dalam suatu bahan, kemurnian serta kebersihan suatu bahan yang dihasilkan.

Gambar 1. Hubungan Kadar Abu dengan Lama Maserasi

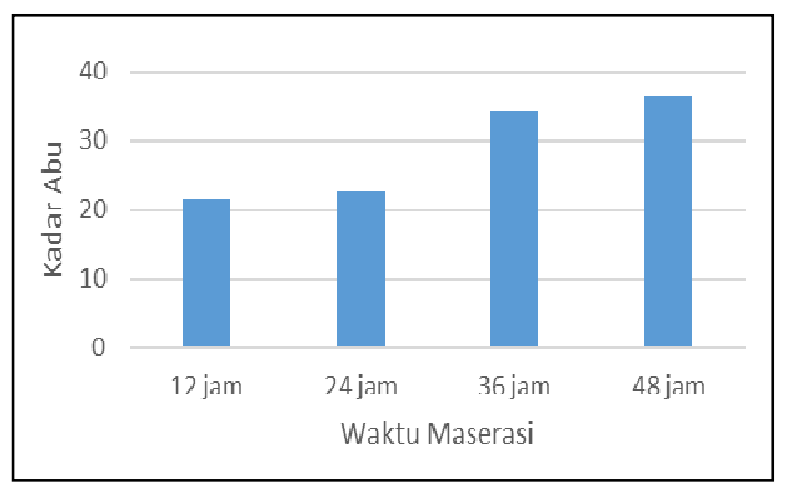

\section{Laundrymeter}

Penilaian laundrymeter dilakukan dengan mengamati adanya perubahan warna asli dari contoh uji (tidak berubah, ada perubahan sedikit perubahan, cukup berubah dan berubah sama sekali),serta dilakukan penodaan warna terhadap kain putih. Penilaian tahan luntur warna dilakukan dengan membandingkan perubahan warna yang terjadi dengan suatu standar perubahan warna yang dikeluarkan oleh SNI ISO 105-C06:2010, yaitu standar skala abu-abu untuk menilai perubahan warna contoh 
uji dan standar skala penodaan untuk menilai penodaan warna pada kain putih.

Dari Tabel 1 dapat diketahui hasil analisa Gray Scale digunakan untuk menilai perubahan warna contoh uji tahan luntur warna. Hasil uji ketahanan terhadap pencucian kain yang telah diaplikasikan, zat warna yang diperoleh dari ekstraksi Grapthophyllum pictum diperoleh nilai tahan luntur 3-4 yang berarti cukup baik sedangkan pada perlakuan 48 jam memiliki nilai ketahan luntur 3 yang berarti cukup. Hal ini diduga zat pewarna pada daun Grapthophyllum pictum berikatan dengan kain katun berdasarkan skala standar abu-abu.

Tabel 1. Hasil pengujian menggunakan laundrymeter

\begin{tabular}{lcl}
\hline Perlakuan & Gray Scale & $\begin{array}{l}\text { Staining } \\
\text { Scale }\end{array}$ \\
\hline 12 jam & $3-4$ & $4-5$ \\
\hline 24 jam & $3-4$ & $4-5$ \\
\hline 36 jam & $3-4$ & $4-5$ \\
\hline 48 jam & 3 & $4-5$ \\
\hline
\end{tabular}

Analisa Staining Scale atau standar skala penodaan warna pada kain putih memiliki nilai 4-5 yang berarti baik. Data tersebut dapat menyimpulkan bahwa semua perlakuan pada berbagai wakttu maserasi memiliki nilai yang sama. Hal ini menjelaskan bahwa pewarna yang berasal dari ekstrak Grapthophyllum pictum yang diaplikasikan pada kain katun meiliki nilai perubahan warna yang baik seperti yang diperlihatkan pada Tabel 1.

Adanya ketahanan luntur yang kuat pada kain dengan bahan fiksasi tawas terhadap pencucian berkaitan dengan terjadinya zat warna Grapthophyllum pictum yang mampu masuk ke dalam serat kain secara maksimum. Hal ini sejalan dengan pernyataan Amalia dan Akhtamimi (2016) melakukan ekstraksi pewarna dari limbah kulit rambutan dengan menggunakan fiksasi tawas $25 \%$ dan $45 \%$ menghasilkan ketahanan luntur warna kain batik 5 yaitu sangat baik. Sulasminingsih (2006) dalam Wijana dkk (2016), bahwa fiksasi kapur tohor terhadap pencucian berkaitan dengan terjadinya ikatan tannin daun alpukat yang mampu masuk ke dalam serat kain secara maksimum dan berikatan kuat dengan serat daun nanas dan katun

\section{Kesimpulan}

Nilai kadar abu pada penelitian ini semakin tinggi, hal ini diduga karena dipengaruhi oleh lamanya waktu maserasi. Hasil uji ketahanan luntur warna terhadap pencucian menunjukkan bahwa ketahanan luntur warna terkuat yaitu pada lama maserasi 12-36 jam dilihat dari nilai Grey Scale dan Stainning Scale dengan deskriptif nilai baik.

\section{Daftar Pustaka}

Amalia dan Akhtamimi.2016. Studi Pengaruh Jenis Dan Konsentrasi Zat Fiksasi Terhadap Kualitas Warna Kain Batik Dengan Pewarna Alam Limbah Kulit Buah Rambutan (Nephelium lappaceum). Dinamika Kerajinan dan Batik 33(2):85-92

Bahri, S., Jalaludin, dan Rosnita. 2017. Pembuatan Zat Warna Alami Dari Kulit Batang Jamblang (Syzygium Cumini) sebagai Bahan Dasar Pewarna Tekstil. Jurnal Teknologi Kimia Unimal, 6(1):1019.

Kasmudjo dan Saktianggi, P.P. 2011. Pemanfaatan Daun Indigofera Sebagai Pewarna Alami Batik. Prosiding Seminar Nasional MAPEKI XIV.

Kwartiningsih, E., 2009. Pembuatan Zat Warna Alami Tekstil dari Kulit Manggis, Laporan Penelitian Teknik Kimia, UNS, Surakarta.

Malik, K., Tokkas, J., and Goyal, S. 2012. Microbial Pigments: a Review. Int. J. Microbial. Resour. Technol, 1: 361-365.

Rymbai, H., Sharma, R.R., and Srivasta, M. 2011. Bio-colorants and Its Implications in Health and Food Industry-A Review. International Journal of Pharmacological Research, 3: 22282244.

Sandjaya dan Atmarita. 2009. Kamus Gizi Perlengkapan Kesehatan Keluarga. Kompas Media Nusantara. Jakarta.

Scully K, Cobb DJ. 2012. Colour Forecasting for Fashion. Laurence King Publishing. 
Visalakshi, M., \& Jawaharlal, M. 2013. Healthy

Hues-Status and Implication in

Industries - Brief Review.Journal of Agriculture and Allied Sciences. 3(2): 4251.

Wijana, S., Dewi, I.A., dan Setyowati, E.D.P. 2016. Aplikasi Pewarna Batik pada Tenun dari Serat Daun Nanas (Kajian Proporsi Jenis Benang dan Jenis Pewarna). Jurnal Teknologi dan Manajemen Agroindustri 5(1): 30-38. 